\title{
Reflexiones ético-políticas sobre la pena de muerte
}

La discusión sobre la reimplantación de la pena de muerte ha ocupado un espacio importante en el debate público durante las últimas semanas. Un eje de la discusión lo ha constituido una encuesta de opinión pública, elaborada por la Universidad Tecnológica, la cual reveló que el 64 por ciento de la población estaría de acuerdo con la implantación de la pena máxima, mientras que el 70 por ciento califica como correcta la salida del ejército a las calles para combatir la delincuencia. Asimismo, los resultados de la encuesta también muestran el rechazo de un porcentaje significativo de la población al gobierno actual, lo cual llevó al diputado de Walter Araujo (ARENA) a manifestar su desconfianza ante los datos de la encuesta y a sostener que "en realidad lo que ha sido presentado a la luz pública sí marca una vaguedad en cuanto a informaciones, en cuanto a ser tocados muy someramente y trivialmente aspectos muy puntuales sin contar con más elementos".

Cuando ARENA anunció que tenía listo el proyecto de ley para reimplantar la pena de muerte en el país, el debate arreció, sobre todo entre las diversas fracciones política de la asamblea legislativa. Sin embargo, el partido en el gobierno todavía no ha presentado en la asamblea el proyecto anunciado. En esos momentos, ARENA tenía sus 39 votos asegurados más cuatro de los diputados del Movimiento Renovación Social Cristiano y otros dos de los diputados del Partido de Concilia- ción Nacional. El Partido Demócrata Cristiano dejaría en libertad a sus diputados, pero el FMLN y Convergencia Democrática se oponían unánimemente. El Movimiento Unidad apoyaría la iniciativa de ARENA, pero antes pediría un debate nacional.

En la discusión también se ha hecho presente el Organo Judicial, por medio de su Vicepresidente, René Hernández Valiente, y del presidente de la Sala de Penal de la Cotte Suprema de Justicia, José María Méndez. Para el primero, la reimplantación de la pena de muerte en el país implica necesariamente renunciar al convenio internacional por el cual El Salvador reconoce la jurisdicción de la Corte Interamericana de Derechos Humanos, lo cual traería complicaciones internacionales a la nación. Más aún, Hernández Valiente no sólo recordó que "el error judicial", es decir, la posibilidad de errar al emitir condenas, había llevado a suprimir la pena capital —porque una vez ejecutada no es posible revocarla o indultarla-. sino que hizo ver que no era competencia de la Corte Suprema discutir el tema, dada su naturaleza político-legislativa. Mientras que para José María Méndez, la reimplantación de la pena de muerte no sólo demuestra la "ineficacia" de los métodos para combatir la delincuencia, sino que es una acción "desesperada" que carece de justificación ideológica y filosofica. Y es que los hechos delictivos, a juicio del jurista, disminuirán con la 
intervención de las instituciones vinculadas con la aplicación de la judicatura, entre ellas el Organo Judicial, la Policía Nacional Civil y el Ministerio Público.

A la discusión se sumó el administrador diocesano de San Salvador, Mons. Gregorio Rosa, quien "rechazó" la propuesta para reimplantar la pena de muerte, "en el fondo es como aceptar una fatalidad". Para el prelado, "la angustia por la delincuencia" es la que motiva a muchos a pedir que se "reimplante" la pena capital, pero sin justificación alguna. En cambio, el arzobispo electo de San Salvador aprobó la medida, invocando la libertad que Juan Pablo II otorga a los estados para aplicarla como medida defensiva de la sociedad.

Mientras diferentes instancias políticas, sociales y eclesiales opinaban sobre las formas más eficaces para enfrentar el auge de la delincuencia, un nuevo grupo paramilitar autodenominado "La sombra negra" hizo su aparición, atribuyéndose el asesinato de varios delincuentes en San Miguel, Santa Ana y San Salvador. Posteriormente, otro grupo clandestino anunció, por medio de un comunicado, el inicio de sus actividades contra la delincuencia común. Este grupo, autodenominado Comando Ejecutivo Antidelincuencial Transitorio (CEAT), justificó su aparición debido a "la enorme lacra social que azota a nuestra nación y a todos los salvadoreños que honradamente ganamos el sustento diario". En su comunicado, el Comando manifiesta "al señor presidente de la república..., al pleno legislativo y a la Corte Suprema de Justicia, que somos un organismo interesado en velar por el orden y la seguridad social, no somos delincuentes sino ciudadanos que deseamos una paz total en nuestro país". Intenta justificar sus acciones invocando el Artículo 2 de la Constitución que establece que "toda persona tiene derecho a la vida, a la integridad física y moral, a la libertad, a la seguridad, al trabajo, a la propiedad y posesión y a ser protegida en la conservación y defensa de los mismos".

El Comando Ejecutivo Antidelincuencial Transitorio declara también que se diferencia de la Policía Nacional Civil en cuanto no goza del apoyo gubernamental y exige un sistema de justicia más eficiente, citando como ejemplo el caso Cromeyer y Kalberg, todavía pendiente de solución. Finalmente, el nuevo grupo clandestino hace un llamado a ADEFAES para que se abstenga de llevar a cabo acciones desestabilizadoras; pide a FENASTRAS que desista de realizar acciones que pongan en peligro la economía del país y responsabiliza a ANDES 21 de Junio del problema de las "maras".

¿Cómo evaluar críticamente, en el marco de las diversas posturas, así como en el marco de grave problema delincuencial que azota al país, la propuesta de reimplantar la pena de muerte?

Pues bien, esta evaluación debe partir, al menos, de la constatación de que la gran mayoría de los que pretenden generar un opinión favorable a la medida apelan al "clima de terror" generado por la ola delincuencial, la cual cotidianamente pone en juego la vida del ciudadano indefenso. Más aún, quienes están a favor de la pena máxima afirman que los delincuentes han declarado la pena de muerte contra los salvadoreños honrados, quienes muchas veces, ante la embestida de que son objeto, se ven forzados a hacer valer la justicia con sus propias manos. Ante esta situación, pues, el Estado tiene que dar una respuesta pronta y eficaz, $y$ esa respuesta consiste en el castigo merecido, extremadamente duro para los delitos más graves.

Justamente, esta es la línea de argumentación que sigue Alfredo B. Parada, en el artículo titulado "Los argumentos sobre la pena de muerte", en el cual cuestiona a quienes están en contra de la mencionada medida. "Los opositores de la pena de muerte se lamentan al igual que todo el mundo del agobiante aumento de la delincuencia... Sin embargo, aquellos [se] oponen [a] la severidad de la pena por ser 'inhumana', no ser 'ejemplarizante', etc. Y es que se olvidan los opositores a la pena de muerte que los salvadoreños estamos condenados, sin excepción y sin debido proceso, a muerte a balazos, a puñaladas desde el mismo instante que salimos de nuestras residencias... La verdad es que las actuales condiciones delincuenciales obligan a nuestras autoridades a un cambio drástico en el sistema punitivo. De tal suerte que la pena de muerte se convierte en una necesidad social" ( $E l$ Diario de Hoy, 25 de abril de 1995, p. 6). 
Al parecer, estamos ante un argumento irrebatible: los que atentan contra la vida tienen que pagar con su vida. Y los que sostienen una tesis semejante apuestan porque la amenaza de pagar con la propia vida un delito será suficiente para contener al criminal en potencia o para, en el caso que se castigue efectivamente a un delincuente activo, sentar un precedente respecto a otros posibles delincuentes. En esta línea de razonamiento, los criminales cometen fechorías porque los castigos establecidos por la sociedad no son lo suficientemente radicales. Un castigo radical, como la pena de muerte, vendría a ser la solución definitiva para el grave problema delincuencial que abate a la sociedad salvadoreña.

Frente a esta postura y aun reconociendo la impunidad con la que actúan los delincuentes y criminales y los peligros que los ciudadanos indefensos enfrentan cotidianamente, otros sectores no aprueban la reimplantación de la pena de muerte por razones éticas que denuncian su carácter deshumanizador y piden para el delincuente la oportunidad para reintegrarse a la sociedad; por razones sociológicas que subrayan los condicionamientos sociales y económicos del comportamiento delictivo, lo cual hace recaer la responsabilidad más en la sociedad y mucho menos en los individuos, quienes vendrían a ser víctimas de estructuras socio-económicas excluyentes y marginadoras; y por razones jurídico administrativas que enfatizan tanto la inadecuación legal para tratar el problema delincuencial como la ineficacia de las instancias encargadas de hacer efectivo el cumplimiento de la ley.

Ciertamente, las razones que se esgrimen para no aprobar la reimplantación de la pena de muerte merecen una detenida consideración por parte de quienes están a favor. Las razones éticas y sociológicas no pueden ser descartadas como producto de una elucubración mental no sustentada en la realidad. $Y$ es que tan real es la violencia cotidiana de la cual son responsables los criminales y delincuentes como la condicionalidad social, económica y cultural de su comportamiento delictivo, así como la necesidad de humanizar las medidas encaminadas a sancionar ese comportamiento. Aquí cabe destacar que negar la condición humana a los criminales y delincuentes puede ser grave no sólo porque con ello se cerraría cualquier opción para su integración social, sino que el Estado estaría asumiendo legítimamente prácticas deshumanizantes, como ya lo hizo antes, sólo que esta vez lo haría amparado en la legalidad y en el clamor de amplios sectores de la sociedad. A quienes creen que a los que violentan la vida no les debe estar permitido vivir -al igual que a los que proclaman con Sain Just, "ninguna para los enemigos de la libertad"-, hay que recordarles que argumentos de ese tipo fueron utilizados por los militares latinoamericanos, bajo los regímenes de seguridad nacional, para cometer las actos violentos más degradantes contra sus enemigos políticos, aquellos a quienes habían calificado ideológicamente como los enemigos de la vida, la libertad, la religión y la propiedad privada.

Asimismo, los argumentos que enfatizan la dimensión jurídico administrativa en el tratamiento del problema delincuencial merecen una consideración especial. ¿Posee la sociedad salvadoreña los instrumentos legales adecuados para enfrentar los desafíos que plantean los complejos problemas de la impunidad, la delincuencia y la criminalidad? ¿Son las instancias responsables de administrar y aplicar las leyes lo suficientemente eficaces para ello? ¿Son estas instancias lo suficientemente independientes de las redes de poder político y económico para garantizar la aplicación irrestricta de la ley? ¿Posee el Estado la "autoridad" y la eficacia suficientes para garantizar el bien común de la sociedad? ¿Existe una expectativa ampliamente compartida y sustentada de que el Estado y sus instancias harán cumplir las leyes?

La experiencia reciente indica que todas estas interrogantes deben ser respondidas de forma negativa. Y, si ello es así, esas mismas interrogantes hacen ver que la respuesta para la compleja problemática de la delincuencia no consiste en reestablecer una penalización mas drástica, como lo es la pena de muerte, sino en reestructurar los mecanismos de funcionamiento de la administración de justicia, tanto en orden a hacerlos más eficaces como en orden a dotarlos de la independencia necesaria respecto a las redes del poder político y económico imperantes en el país. 
Sólo la "puesta a prueba" de la eficacia de las instituciones encargadas de administrar la justicia, así como la penalización de todos aquellos que violentan la legalidad, puede contribuir crear una expectativa ampliamente compartida y sustentada de que el Estado y sus instancias harán cumplir la ley. Cuando esto vaya sucediendo, la impunidad irá perdiendo terreno. Y es que la impunidad, justamente, se instituye cuando individuos o grupos determinados perciben que no sólo pueden violentar la ley, sino que no existen instancias capaces de pedirles cuentas por ello. Aquí no importa tanto cual sea la naturaleza de los castigos estipulados para lo delitos que se cometen, sino si esos castigos pueden aplicarse a los que violan las leyes. Cuando existe la percepción de que esos castigos no pueden aplicarse o que pueden evadirse por razones de poder político, económico o militar, entonces, la autoridad del Estado y su compromiso de garantizar el bien común han fracasado.

En este contexto, es oportuno traer a cuenta la siguiente reflexión de Guillermo O'Donnel sobre la naturaleza del Estado y sus responsabilidades socio-políticas. "El Estado" — señala O'Donnel-

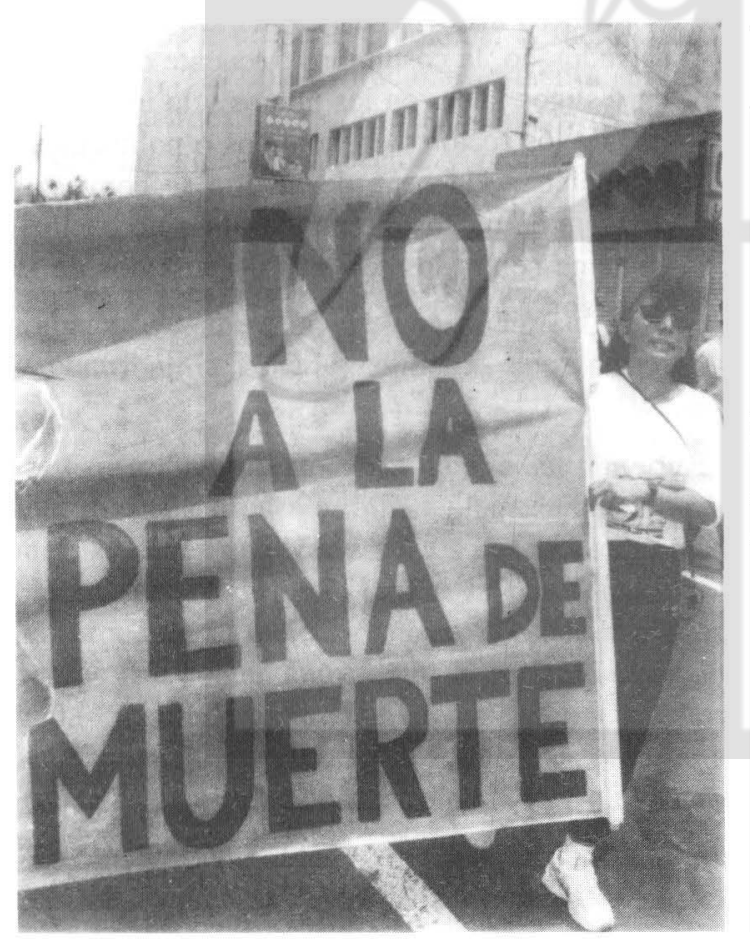

"también es... un conjunto de relaciones sociales que establece un cierto orden y en última instancia lo respalda con una garantía coercitiva centralizada, sobre un territorio dado. Muchas de estas relaciones se formalizan en un sistema legal surgido del Estado y respaldado por él... El sistema legal es una dimensión constitutiva del Estado y del orden que éste establece y garantiza en un cierto territorio... La efectividad de la ley en un territorio consiste en innumerables comportamientos habituales que por lo general (conscientemente o no) son compatibles con lo que prescribe la ley... Esa efectividad se basa en la expectativa, ampliamente compartida y sustentada en casos que obran como modelo ejemplar, de que dicha ley, de ser necesario, será impuesta por una autoridad central dotada de los poderes pertinentes" ("Acerca del Estado, la democratización y algunos problemas conceptuales", en J. Barba y M. Lungo, Estado y mercado, San Salvador, 1995).

De este modo, el Estado, como detentador legítimo de los instrumentos de coerción propios de la sociedad, tiene que ser capaz de generar la expectativa entre los miembros de aquélla de que la ley será restituida eficazmente cuando sea violentada por cualesquiera de ellos, sin importar su condición social, política o económica. Es decir, el Estado no sólo debe ser efectivo en el cumplimiento de la ley -determinando responsabilidades, investigando exhaustivamente las prácticas ilegales y sancionando a los culpables-, sino que debe hacer valer su universalidad, garantizando que "cualquiera pueda apelar a ella con éxito, independientemente de su posición en la sociedad" $(\mathrm{O}$, Donnel). Esta doble condición -eficacia en la aplicación de la ley y defensa de su universalidad- es decisiva para que los miembros de la sociedad no sólo se sientan parte de la comunidad política (ciudadanos), sino para que los violentadores potenciales de la legalidad asuman dentro de sus expectativas que el Estado está allí para pedirles cuentas de sus actos.

¿Cómo leer la realidad judicial salvadoreña a partir de lo anterior? ¿Qué decir de la efícacia y universalidad del Estado en la aplicación de las leyes?

En El Salvador existen en la actualidad sancio- 
nes drásticas para castigar a los que violan las leyes. El asunto es que esas sanciones no han llegado a aplicarse en un gran número de casos debido al poder de los implicados, así como a la corrupción que aún constituye un lastre en la administración de justicia. Por tanto, no se puede afirmar que las leyes se violentan porque las penalizaciones no son lo suficientemente drásticas cuando en casos graves de violación a dichas leyes, sobre todo en las dos ultimas décadas, la aplicación de las mismas no se ha consumado, debido al modo cómo ha sido administrada la justicia.

Es decir, el Estado salvadoreño atraviesa por un serio problema de eficacia en la administración de justicia, cuyo centro no son las sanciones a aplicar a los criminales, sino la efectividad de los mecanismos orientados a prevenir, controlar y sancionar como es debido a los responsables de algún delito. Son esos mecanismos los que no funcionan en el país, como lo demuestra el desenlace de innumerables casos judiciales, en los cuales la misma administración de justicia se ha puesto a favor de delincuentes reconocidos. Pero también, debido en parte a lo anterior, el Estado salvadoreño atraviesa por un déficit en su capacidad para presentarse como garante de la aplicación universal de la ley - porque los que tienen alguna cuota de poder muestran que pueden sustraerse a la misma-, lo cual merma severamente la legitimidad estatal y debilita las expectativas acerca de la aplicación irrestricta de su poder.

En definitiva, si se ha de defender una argumentación contra la pena de muerte, esta debería asumir, cuando menos, tres de los cinco puntos expuestos por la Compañía de Jesús en su comuni- cado sobre la pena de muerte:

(a) "En la actualidad el Estado moderno cuenta con posibilidades suficientes para luchar contra la delincuencia sin necesidad de acudir a la pena de muerte. Si los gobiernos no invierten adecuadamente los fondos del erario público en la prevención del delito, en la reforma del sistema judicial, en el seguimiento, control y trabajo de readaptación del delincuente joven, la pena de muerte, aun resultando más barata, no soluciona el problema de la delincuencia";

(b) "Los gobiernos pasados, así como el presente, no han invertido adecuadamente ni en la prevención del delito, ni en sistemas de seguridad policial, ni en la reforma del sistema judicial, todavía muy deficiente; ni en el seguimiento y atención del joven delincuente. Acudir a la pena de muerte como solución de la delincuencia, sin haber cumplido con los requisitos anteriormente expresados, es el equivalente a recurrir a los escuadrones de la muerte para luchar contra la subversión: un acto irresponsable que puede acelarar la violencia en lugar de frenarla".

(c) "Dadas las deficiencias del sistema judicial salvadoreño, la costumbre frecuente de presentar testigos falsos en los juicios y la impunidad real de los sectores económicos o políticamente pudientes, la pena de muerte se convertirá de facto en un castigo parcial dirigido exclusivamente contra los sectores desposeídos de El Salvador".

L. A. G. 